Check for updates

Cite this: RSC Adv., 2019, 9, 16566

Received 26th April 2019

Accepted 21st May 2019

DOI: $10.1039 / c 9 r a 03111 a$

rsc.li/rsc-advances

\section{Colorimetric detection of hydrogen peroxide and glucose by exploiting the peroxidase-like activity of papain $\dagger$}

\author{
Yuye Chen, ${ }^{a}$ Qingmei Zhong, ${ }^{a}$ Yilin Wang, (D) *ab Chunling Yuan, ${ }^{a}$ Xiu Qin ${ }^{a}$ \\ and Yuanjin $\mathrm{Xu}^{\mathrm{a}}$
}

Papain, a natural plant protease that exists in the latex of Carica papaya, catalyzes the hydrolysis of peptide, ester and amide bonds. In this work, we found that papain displayed peroxidase-like activity and catalyzed the oxidation of $3,3^{\prime}, 5^{\prime}, 5^{\prime}$-tetramethylbenzidine (TMB) in the presence of $\mathrm{H}_{2} \mathrm{O}_{2}$. This results in the formation of a blue colored product with an absorption maximum at $652 \mathrm{~nm}$. The effects of experimental parameters including $\mathrm{pH}$ and reaction temperature on catalytic activity of papain were investigated. The increase of absorbance induced by the catalytic effect of papain offers accurate detection of $\mathrm{H}_{2} \mathrm{O}_{2}$ in the range of 5.00-90.0 $\mu \mathrm{M}$, along with a detection limit of $2.10 \mu \mathrm{M}$. A facile colorimetric method for glucose detection was also proposed by combining the glucose oxidase (GOx)-catalyzed glucose oxidation and papain-catalyzed TMB oxidation, which exhibited a linear response in the range of $0.05-0.50 \mathrm{mM}$ with a detection limit of $0.025 \mathrm{mM}$. The method proposed here displayed excellent selectivity, indicating that common coexisting substances (urea, uric acid, ascorbic acid, maltose, lactose and fructose) in urine did not interfere with detection of glucose. More importantly, the suggested method was successfully used to precisely detect the glucose concentration in human urine samples with recoveries over $96.0 \%$.

\section{Introduction}

In clinical diagnosis, several disease-related biomolecules (such as glucose, ${ }^{1}$ uric acid, ${ }^{2}$ and sarcosine ${ }^{3}$ ) are generally measured via indirect colorimetric analysis. Namely, these biomolecules are oxidized with the catalysis of corresponding oxidase enzymes, then, hydrogen peroxide $\left(\mathrm{H}_{2} \mathrm{O}_{2}\right)$ is quantitatively produced, which can yield hydroxyl radicals $(\cdot \mathrm{OH})$ by the catalysis of peroxidase (such as horseradish peroxidase, HRP). After that, the hydroxyl radical is able to oxidize $3,3^{\prime}, 5,5^{\prime}$-tetramethylbenzidine (TMB) into oxidized TMB with an absorption peak at $652 \mathrm{~nm}$. Thus the content of the biomolecule can be finally determined by measuring the absorbance at $652 \mathrm{~nm}$. This method does not need any sophisticated instrumentation and can achieve rapid visual detection of target molecules, ${ }^{\mathbf{4}-6}$ which makes it feasible, fast and cost-effective. ${ }^{7,8}$ In addition, HRP, as a biological catalyst, possesses remarkable advantages such as high substrate specificities and high efficiency under mild conditions, which makes the method highly selective with less interference. ${ }^{9}$ Of course, as a natural enzyme, HRP has

${ }^{a}$ School of Chemistry and Chemical Engineering, Guangxi University, Guangxi Key Laboratory of Biorefinery, Nanning 530004, China

${ }^{b}$ Guangxi Key Laboratory for Agro-Environment and Agro-Product Safety, Nanning 530004, China. E-mail: theanalyst@163.com; Tel: +86 7713392879

$\dagger$ Electronic supplementary information (ESI) available. See DOI: 10.1039/c9ra03111a inherent disadvantages of high cost, difficult preparation, low stability, and easily denaturing in extreme conditions, which impedes its widespread applications. ${ }^{10}$ Therefore, much effort has been done in exploration of peroxidase-like to replace HRP in the construction of enzymatic assays. A series of nanomaterials, including noble metals $\left(\mathrm{Au},{ }^{11} \mathrm{Ag},{ }^{12} \mathrm{Pt},{ }^{13} \mathrm{Pd}^{14}\right.$ and $\left.\mathrm{Rh}^{15}\right)$, transition metal oxides or chalcogenides $\left(\mathrm{Fe}_{3} \mathrm{O}_{4}{ }^{16}\right.$ $\mathrm{Co}_{3} \mathrm{O}_{4},{ }^{17} \mathrm{CeO}_{2},{ }^{18} \mathrm{VS}_{2},{ }^{19} \mathrm{CuS},{ }^{20} \mathrm{Fe}_{3} \mathrm{~S}_{4},{ }^{21}$ et al.), and carbon-based nanomaterials, ${ }^{22-25}$ have been reported to exhibit the highly peroxidase-like activity, which have been used as peroxidase mimetic for the detection of $\mathrm{H}_{2} \mathrm{O}_{2}$, glucose, uric acid, etc. Although these nano-enzymes are important, they suffer from drawbacks such as high cost, time-consuming and tedious preparation of nanomaterials. Moreover, poor stability and biocompatibility of the nanomaterials also limit their practical applications. ${ }^{26}$ Therefore, it is quite necessary for researchers to explore new natural enzymes with wide sources and low cost, and apply them in colorimetric analysis. Zheng's group reported that ficin exhibited significant peroxidase-like activity, which had been used for colorimetric detection of glucose ${ }^{27}$ and uric acid, ${ }^{28}$ individually.

Papain, a natural plant protease exists in the latex of Carica papaya, catalyzes the hydrolysis of peptide, ester and amide bonds. It is recognized as a sulfhydryl protease, the active site is located at the interface of L- and R-domains in the form of a V shaped cleft and is formed by a cysteine, a histidine, from an asparagine and a glutamine residue. ${ }^{29}$ Because of its good 
stability, high protein hydrolysis ability and good degradation effect on many kinds of proteins, papain, one of the industrial proteases, has been widely used in food, medicine, feed, cosmetics, leather, and textile industries..$^{30,31}$ In this work, we reported for the first time that papain exhibited significant peroxidase-like activity, which could catalyze oxidation of TMB in the presence of $\mathrm{H}_{2} \mathrm{O}_{2}$ to produce blue color. It is well known that $\mathrm{H}_{2} \mathrm{O}_{2}$ is the product of the oxidation of glucose. Therefore, a simple colorimetric method was developed for the detection of glucose based on the glucose oxidase (GOx)-catalyzed glucose oxidation and papain-catalyzed TMB oxidation (Scheme 1). And this method was applied for the detection of glucose in urine samples with satisfactory results.

\section{Experimental section}

\subsection{Chemicals and instruments}

All the chemicals in this study were of analytical grade and used as received. Papain, glucose, glucose oxidase (GOx) and 3,3',5,5'tetramethylbenzidine (TMB) were obtained from Macklin Biochemical Reagent (Shanghai, Co., Ltd., China). N,N-Dimethylformamide (DMF), acetic acid (HAc), sodium acetate (NaAc), hydrogen peroxide $\left(\mathrm{H}_{2} \mathrm{O}_{2}\right)$, urea, uric acid, ascorbic acid, maltose, lactose, and fructose were acquired from Da Mao Chemical Reagents (Tianjin, China). TMB was dissolved in DMF, doubly deionized water (DDW) was used throughout.

Absorption spectra were recorded using a UV-4802 spectrophotometer (Unico, Shanghai, China) equipped with a $1.0 \mathrm{~cm}$ cuvette. The $\mathrm{pH}$ of the solutions was monitored with a PXSJ-216 $\mathrm{pH}$ meter (Shanghai Precision Science Instrument Co., Ltd., China).

\subsection{Procedure for determination of $\mathrm{H}_{2} \mathrm{O}_{2}$ and glucose}

$\mathrm{H}_{2} \mathrm{O}_{2}$ detection was performed as follows: $100 \mu \mathrm{L} 100 \mu \mathrm{g} \mathrm{mL}^{-1}$ papain, $1.0 \mathrm{~mL} 5.0 \mathrm{mM} \mathrm{TMB}$, and $1.0 \mathrm{~mL} \mathrm{H}_{2} \mathrm{O}_{2}$ solution with different concentrations were added sequentially in $7.9 \mathrm{~mL}$ NaAc-HAc (pH 3.5) buffer. The mixture was incubated at $40{ }^{\circ} \mathrm{C}$ for $20 \mathrm{~min}$ then kept in an ice-water bath for $10 \mathrm{~min}$ to stop the reaction. Finally, the UV-vis spectroscopy of the resultant solution was scanned from 500 to $800 \mathrm{~nm}$ at room temperature, and the absorbance at $652 \mathrm{~nm}$ was used for quantitative analysis.

Glucose detection was carried out as follows: $0.2 \mathrm{~mL}$ GOx of $1.0 \mathrm{mg} \mathrm{mL} \mathrm{m}^{-1}$ and $1.0 \mathrm{~mL}$ of different concentrations of glucose were added into $1.0 \mathrm{~mL}$ phosphate buffer $(\mathrm{pH} 7.0)$ and then incubated at $37{ }^{\circ} \mathrm{C}$ for $40 \mathrm{~min}$. Subsequently, the glucose reaction solution was added into $7.8 \mathrm{~mL}$ HAc-NaAc (pH 3.5) buffer

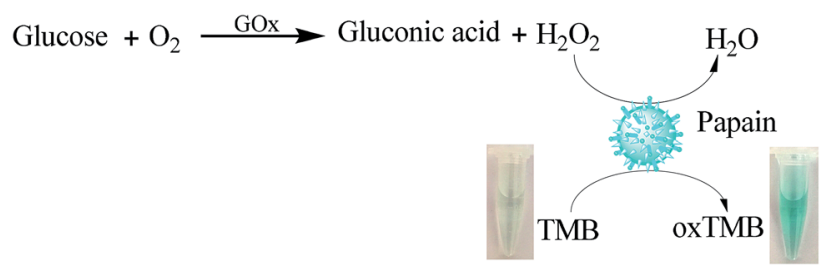

Scheme 1 Schematic illustration of the peroxidase-like activity of papain for the colorimetric detection of glucose by coupling with glucose oxidase (GOx) catalysis. containing $0.5 \mathrm{mM} \mathrm{TMB}$ and $1.0 \mu \mathrm{g} \mathrm{m \textrm {m } ^ { - 1 }}$ papain. The mixture was incubated at $40^{\circ} \mathrm{C}$ for $20 \mathrm{~min}$ then kept in an ice-water bath for $10 \mathrm{~min}$ to stop the reaction. The resultant solution was monitored by the UV-vis spectroscopy.

The selectivity of the proposed detection system was assessed by adding potential interfering substances coexisting in human urine (such as urea, uric acid, ascorbic acid, maltose, lactose, fructose) instead of glucose in a same way. The final concentrations of the interfering substances were all $8.0 \mu \mathrm{M}$.

\subsection{Analysis of real samples}

The morning urine samples were centrifuged at $12000 \mathrm{rpm}$ for 40 minutes to collect the supernatant for experiment. And then various amounts of glucose were spiked to the urine samples. Finally, the sample detection was carried out using above procedure.

\section{Results and discussion}

\subsection{Intrinsic peroxidase-like activity of papain}

The peroxidase-like activity of papain was investigated through catalytic oxidation of TMB by papain in the presence of $\mathrm{H}_{2} \mathrm{O}_{2}$ and monitoring the absorption spectra. As shown in Fig. 1, the interaction of TMB with papain in the presence of $\mathrm{H}_{2} \mathrm{O}_{2}$ leads to the formation of deep blue colored product with a strong absorption peak at $652 \mathrm{~nm}$, which is similar to the typical HRPcatalyzed oxidation of TMB. ${ }^{32}$ In contrast, the control experiment of TMB with papain in the absence of $\mathrm{H}_{2} \mathrm{O}_{2}$ does not lead to the generation of blue color (Fig. 1 inset), and TMB with $\mathrm{H}_{2} \mathrm{O}_{2}$ in the absence of papain only results in a negligible blue color, which absorbance of corresponding absorption spectra is very low at $652 \mathrm{~nm}$, indicating that both papain and $\mathrm{H}_{2} \mathrm{O}_{2}$ are required for the reaction to occur. These results demonstrate that papain exhibits peroxidase-like activity, which can accelerate TMB oxidation in the presence of $\mathrm{H}_{2} \mathrm{O}_{2}$. It was reported

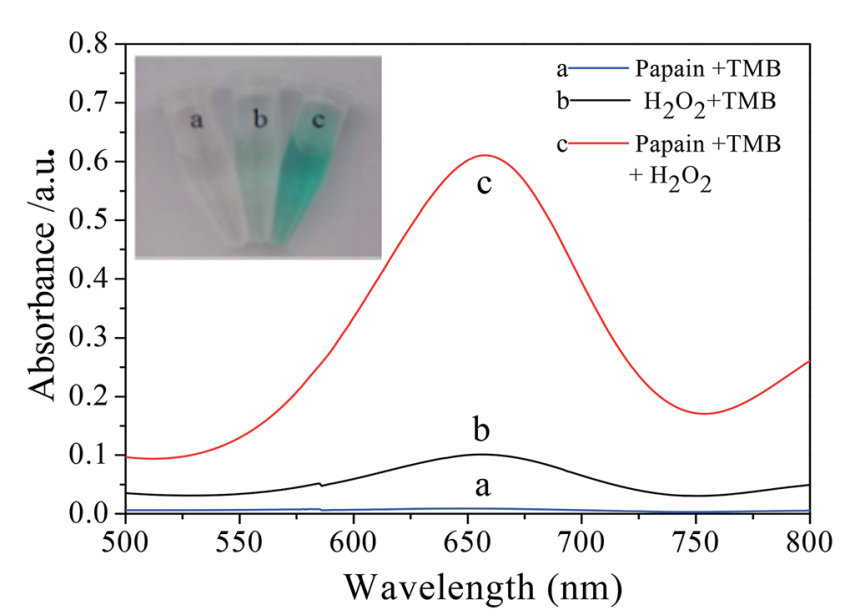

Fig. 1 Papain shows intrinsic peroxidase-like activity. The absorption spectra and colors of TMB in different reaction systems: (a) papain + TMB, (b) $\mathrm{H}_{2} \mathrm{O}_{2}+\mathrm{TMB}$, (c) papain + TMB $+\mathrm{H}_{2} \mathrm{O}_{2}$ (other conditions: 100 $\mu \mathrm{L}$ of $100 \mu \mathrm{g} \mathrm{mL}{ }^{-1}$ papain; $1 \mathrm{~mL}$ of $5.0 \mathrm{mM} \mathrm{TMB}$; $1 \mathrm{~mL}$ of $50 \mu \mathrm{M} \mathrm{H}_{2} \mathrm{O}_{2}$; $\mathrm{pH}=3.5$; reaction temperature is $35^{\circ} \mathrm{C}$; reaction time is $20 \mathrm{~min}$.). 

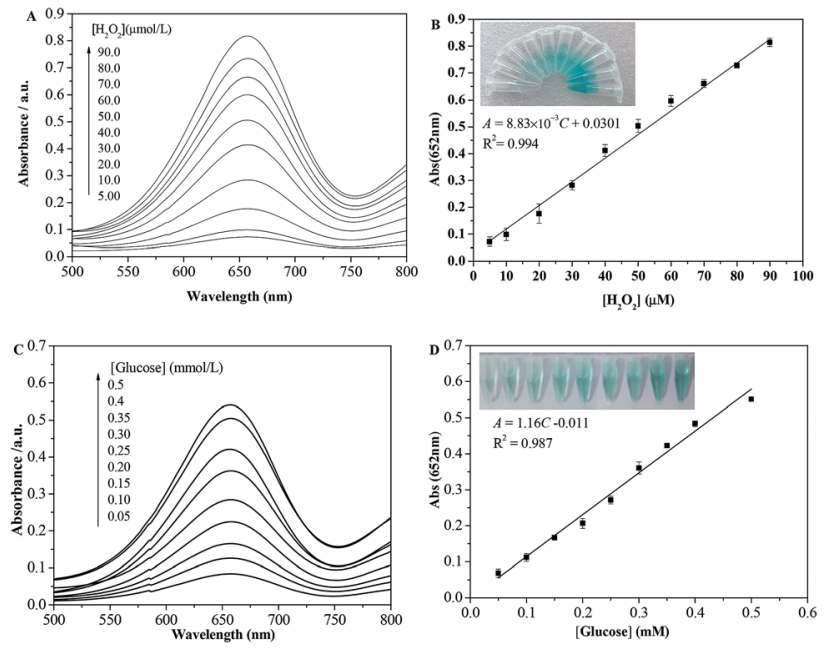

Fig. 2 (A) UV-vis absorption spectra of papain-TMB solution containing $\mathrm{H}_{2} \mathrm{O}_{2}$ concentrations varied from 5.00 to $90.0 \mu \mathrm{M}$. (B) The relation between the absorbance at $652 \mathrm{~nm}$ and the $\mathrm{H}_{2} \mathrm{O}_{2}$ concentrations. (C) UV-vis absorption spectra of glucose-GOx-TMB-papain system in the presence of different concentration of glucose. (D) The calibration curve for glucose determination. Inset: Photographs for colorimetric detection of (B) $\mathrm{H}_{2} \mathrm{O}_{2}$ and (D) glucose, respectively.

that nanomaterials with peroxidase-like activity also had the same effect. ${ }^{33-35}$

\subsection{Steady-state kinetic analysis of papain}

To further investigate the catalytic activity of the papain, apparent steady-state kinetic parameters for papain catalyzed reaction were determined by varying the concentration of TMB and $\mathrm{H}_{2} \mathrm{O}_{2}$. The experiments were performed at $40{ }^{\circ} \mathrm{C}$ using 1.0 $\mu \mathrm{g} \mathrm{mL}^{-1}$ of papain in $0.1 \mathrm{M}$ HAc-NaAc buffer ( $\mathrm{pH} 3.5$ ) containing either $5.0 \mathrm{mM} \mathrm{H} \mathrm{H}_{2} \mathrm{O}_{2}$ with different concentrations of TMB (0.5-3.0 mM) or $1.0 \mathrm{mM}$ TMB with different concentrations of $\mathrm{H}_{2} \mathrm{O}_{2}(0.25-2.0 \mathrm{mM})$. After incubating for 20 minutes, the reaction was stopped with cold water. Then the absorbance of oxidized TMB at $652 \mathrm{~nm}$ were recorded, and the concentration of oxidized TMB were estimated using Beer-Lambert law (molar extinction coefficient, $\varepsilon=3.9 \times 10^{4} \mathrm{M}^{-1} \mathrm{~cm}^{-1}$ ). ${ }^{36}$ The reaction velocities were calculated and plotted against concentration of TMB or $\mathrm{H}_{2} \mathrm{O}_{2}$. As shown, typical Michaelis-Menten curves are observed for both TMB and $\mathrm{H}_{2} \mathrm{O}_{2}$ (Fig. S1A and $\mathrm{B} \dagger$ ). Double-reciprocal curves were plotted (Fig. S1C and $\mathrm{D}_{\dagger}^{\dagger}$ ) and fitted to the equation $1 / V=\left(K_{\mathrm{m}} / V_{\max }\right) \times(1 /[\mathrm{S}])+\left(1 / V_{\max }\right)$, where $V$ is the initial velocity, $V_{\mathrm{m}}$ represents the maximal reaction velocity, [S] corresponds to the concentration of substrate and $K_{\mathrm{m}}$ is the Michaelis constant. We obtained $K_{\mathrm{m}}$ and $V_{\max }$ from the slope and intercept of the curves. The results given in Table $\mathrm{S} 1 \dagger$ show that the $K_{\mathrm{m}}$ value of papain towards TMB and $\mathrm{H}_{2} \mathrm{O}_{2}$ both are larger than those of HRP and ficin, ${ }^{37}$ implying that higher TMB and $\mathrm{H}_{2} \mathrm{O}_{2}$ concentrations are needed for papain to achieve maximal reaction velocity than those for HRP and ficin. The derived catalytic constant $\left(K_{\text {cat }}\right)$ was also taken to compare the enzymatic catalytic activity. The $K_{\text {cat }}$ values of papain with TMB and $\mathrm{H}_{2} \mathrm{O}_{2}$ as the substrates are close to those of ficin, suggesting that papain can also act as an efficient peroxidase mimic.

\subsection{Optimization of experimental conditions}

Similar to the nature of enzymes and other nanomaterials based mimics, the catalytic activity of papain is dependent on $\mathrm{pH}$, temperature, and time. In this work, the peroxidase-like activity of papain was evaluated at different $\mathrm{pH}$ (from 2.5 to 5.5), incubation temperature $\left(25\right.$ to $50{ }^{\circ} \mathrm{C}$ ), and incubation time (from 5 to $30 \mathrm{~min}$ ).

Papain is a kind of biological catalyst, easily denatured at unsuitable $\mathrm{pH}$ values or high temperature. Therefore, the catalytic activity of papain is remarkably influenced by $\mathrm{pH}$ and incubation temperature. As shown in Fig. $\mathrm{S} 2, \dagger$ an increase in $\mathrm{pH}$ from 2.5 to 3.5 results in the increased absorbance whereas a further increase in $\mathrm{pH}$ from 3.5 to 4.5 leads to a gradual decrease. The maximum of absorbance is obtained at $\mathrm{pH} 3.5$, indicating that the oxidation of TMB occurs under weakly acidic condition, which is consistent with that reported for the oxidation of TMB and thus the $\mathrm{pH}$ is adopted. The incubation temperature-dependent response curve is shown in Fig. S3. $\dagger$ The catalytic activity of papain greatly increases as the incubation temperature increases from 25 to $40{ }^{\circ} \mathrm{C}$. Further increase in temperature gives rise to a decrease in catalytic activity, attributed to the inactivation of papain at high temperature. The effect of incubation time was optimized (Fig. S4†). A longer incubation time enables the substrate TMB to react with $\mathrm{H}_{2} \mathrm{O}_{2}$ more completely. The increase of absorbance slows down obviously when the incubation time exceeds $20 \mathrm{~min}$. Therefore, the optimal $\mathrm{pH}$ value, incubation temperature, and incubation time are $3.5,40{ }^{\circ} \mathrm{C}$, and $20 \mathrm{~min}$, respectively.

Table 1 Comparison of different methods for glucose detection

\begin{tabular}{|c|c|c|c|c|}
\hline Method & Materials & $\begin{array}{l}\text { Linear range } \\
(\mu \mathrm{M})\end{array}$ & $\begin{array}{l}\text { Detection limit } \\
(\mu \mathrm{M})\end{array}$ & Ref. \\
\hline Fluorimetry & SGOx-NFs-Amplex Ultra Red & $0-100$ & 3.5 & 38 \\
\hline Fluorimetry & $\mathrm{WS}_{2}$ QDs & $1-60$ & 0.3 & 40 \\
\hline Fluorimetry & Mn-doped $\mathrm{Zn}_{0.5} \mathrm{Cd}_{0.5} \mathrm{~S} @ Z n S$ NRs & $50-300$ & 0.1 & 41 \\
\hline Colorimetry & $\mathrm{Cu}_{2}(\mathrm{OH})_{3} \mathrm{Cl}-\mathrm{CeO}_{2}$ NPs-TMB & $100-2000$ & 50 & 42 \\
\hline Colorimetry & N-GQDs-TMB & $25-375$ & 16 & 45 \\
\hline Colorimetry & Papain-TMB & $50-500$ & 25 & This work \\
\hline
\end{tabular}




\subsection{Detection of $\mathrm{H}_{2} \mathrm{O}_{2}$ and glucose}

Since the absorbance of oxidized TMB at $652 \mathrm{~nm}$ was associated with $\mathrm{H}_{2} \mathrm{O}_{2}$ concentration, a simple method was developed for the detection of $\mathrm{H}_{2} \mathrm{O}_{2}$ spectrophotometrically. Fig. 2A displays the UV-vis absorption spectra of papain-TMB solution containing $\mathrm{H}_{2} \mathrm{O}_{2}$ with different concentrations. As seen, the absorbance at $652 \mathrm{~nm}$ increases with the increase of $\mathrm{H}_{2} \mathrm{O}_{2}$ concentration, and fits a linear regression equation of $A=8.83 \times 10^{-3} C+$ 0.0301 over the range of 5.00-90.0 $\mu \mathrm{M}$ (Fig. 2B). The limit of detection for $\mathrm{H}_{2} \mathrm{O}_{2}$ is calculated to be $2.10 \mu \mathrm{M}(3 \sigma / k)$, showing a high sensitivity for $\mathrm{H}_{2} \mathrm{O}_{2}$ analysis. Simultaneously, the color change of the solution is obvious and easily observed by the naked-eye (Fig. 2B inset). As $\mathrm{H}_{2} \mathrm{O}_{2}$ is the main product of GOxcatalyzed glucose oxidation, colorimetric detection of glucose can be realized when the papain-catalyzed TMB oxidation is coupled with the GOx-catalyzed glucose oxidation. Fig. 2C presents the UV-vis absorption spectra for glucose detection under the optimal conditions and the absorbance at $652 \mathrm{~nm}$ increases gradually with the increase of glucose concentration. As observed in Fig. 2D, the absorbance is proportional to the glucose concentration ranging from 0.05 to $0.50 \mathrm{mM}$ with the detection limit of $0.025 \mathrm{mM}$ glucose. The linear regression equation is $A=1.16 C(\mathrm{mM})-0.011$ with a correlation coefficient of 0.987 . Moreover, the color variation for the glucose response is also obvious by visual observation (Fig. 2D inset).

In Table 1, we compared the analytical performance of the proposed method with those reported methods. As described in Table 1, the linear range of our method is wider than or comparable to some of theirs. Although the detection limit of our method is not the lowest, it provides an alternative method for the detection of glucose in real samples. It is remarkable that almost all of the reported methods require the preparation of probes or nanomaterials while our method does not need.

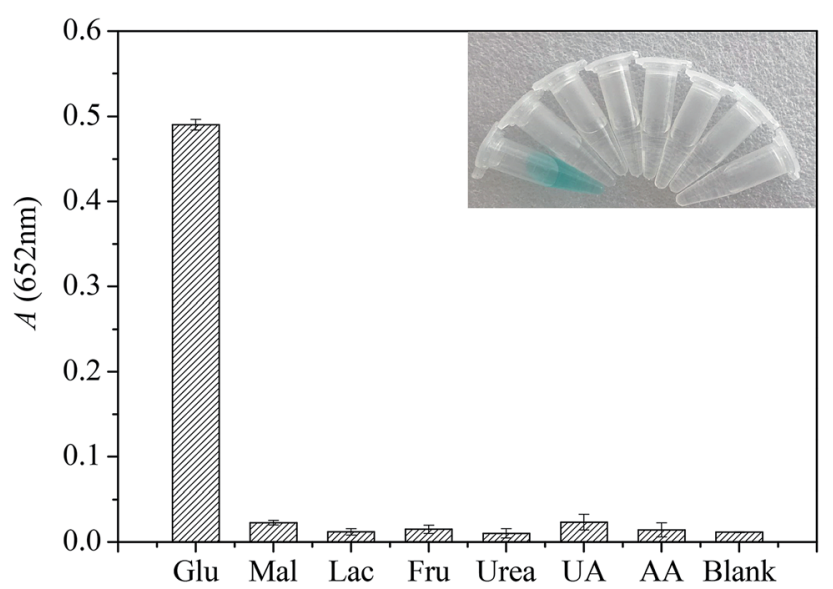

Fig. 3 Selectivity of the proposed method for the detection of glucose. Each potential interfering substance was separately added into reaction solution in the absence of glucose. The concentration of glucose was $0.4 \mathrm{mM}$, and the concentration of the potential interfering substances was $8.0 \mathrm{mM}$. Inset: Typical photograph of glucose detection with the colorimetric method using GOx and papain as the catalysts (from left to right: glucose, maltose, lactose, fructose, urea, uric acid, ascorbic acid and blank).
Table 2 Determination results of glucose in urine samples $(n=3)$

\begin{tabular}{lllll}
\hline Sample & Addition $/(\mathrm{mM})$ & Recovery $/(\mathrm{mM})$ & RSD $/ \%$ & Recovery $\%$ \\
\hline 1 & 0.10 & 0.097 & 3.2 & 96 \\
2 & 0.20 & 0.21 & 2.4 & 104 \\
3 & 0.30 & 0.31 & 2.6 & 104 \\
\hline
\end{tabular}

Thus it can be derived the suggested method is fast and convenient.

In order to evaluate the selectivity of glucose detection, control experiments were conducted with potential interfering substances with urea, uric acid (UA), ascorbic acid (AA), maltose (Mal), lactose (Lac) and fructose (Fru) in solution at concentration of $8.0 \mathrm{mM}$. As shown in Fig. 3, only the addition of glucose can induce a dramatic change in absorbance and an obvious color change (Fig. 3 inset), whereas little changes are observed in the presence of other interference substances, even the concentration of these substances is 20 -fold higher than that of glucose. The results clearly indicate that those existing interferences are inert to glucose detection, hinting that the present method displays a high selectivity toward glucose. Therefore, this study proposed colorimetric analysis method does not require complicated sample processing and can be used for selective detection of glucose in urine samples.

\subsection{Analytical applications}

Based on the activity of papain's peroxidase and glucose oxidase, this method has been successfully used in the detection of glucose in human urine samples from healthy volunteers who are three of our research group. Before the test, morning urine was taken and the supernatant was centrifuged for 40 minutes at a speed of $12000 \mathrm{rpm}$ for analysis. The results of the determination and recovery are shown in Table 2 . It is found that the average recoveries of the glucose are in the range of $96 \%$ to $104 \%$, and the relative standard deviation values of the measurements are from $2.4 \%$ to $3.2 \%$. High recovery and good precision of glucose determination suggest that the proposed colorimetric method can greatly reduce the matrix effect of the human urine sample. These results clearly indicate the feasibility of this method for the determination of glucose in biological samples.

\section{Conclusions}

In conclusion, we reported for the first time that papain exhibited significant peroxidase-like activity, which could catalyze the oxidation of TMB by $\mathrm{H}_{2} \mathrm{O}_{2}$ to produce blue color and the catalytic activity was strongly dependent on $\mathrm{pH}$ and temperature. Based on papain peroxidase-like catalytic activity and GOx, a simple, cheap, and highly selective colorimetric method for the detection of glucose in human urine samples was developed. There is no denying that the catalytic efficiency of papain is lower than HRP and some nano-enzymes. However, compared with other reported methods, the suggested method does not need expensive reagents and tedious procedures for preparing nanomaterials. It is expected that this work will open 
up the possibility of using papain as a substitute for horseradish peroxidase in biochemistry.

\section{Conflicts of interest}

There are no conflicts to declare.

\section{Acknowledgements}

The present work was supported by the Natural Science Foundation of China (21567002), the Opening Project of Guangxi Key Laboratory for Agro-Environment and Agro-Product Safety (17259-82) and the Dean Project of Guangxi Key Laboratory of Bio refinery (GXKLB-201801).

\section{References}

1 C. K. Wang, J. Y. Li, R. Tan, Q. Q. Wang and Z. X. Zhang, Analyst, 2019, 144, 1831-1839.

2 Y. Y. Sheng, H. L. Yang, Y. Wang, L. Han, Y. J. Zhao and A. P. Fan, Talanta, 2017, 166, 268-274.

3 J. M. Lan, W. M. Xu, Q. P. Wan, X. Zhang, J. Lin, J. H. Chen and J. Z. Chen, Anal. Chim. Acta, 2014, 825, 63-68.

4 X. H. Hu, C. Li, C. Feng, X. X. Mao, Y. Xiang and G. X. Li, Chem. Commun., 2017, 53, 4692-4694.

5 H. Chen, Y. Sun, Y. F. Li, J. Zhao and Y. Cao, Microchim. Acta, 2018, 185, 451.

6 X. X. Mao, Y. F. Li, P. Han, X. H. Wang, S. Q. Yang, F. Zhang, X. Q. Gong and Y. Cao, Sens. Actuators, B, 2018, 267, 336-341.

7 Y. M. Leng, K. Xie, L. Q. Ye, G. Q. Li, Z. W. Lu and J. B. He, Talanta, 2015, 139, 89-95.

8 Y. M. Leng, K. Jiang, W. T. Zhang and Y. H. Wang, Langmuir, 2017, 33, 6398-6403.

9 J. Chen, Q. Chen, J. Y. Chen and H. D. Qiu, Microchim. Acta, 2016, 183, 3191-3199.

10 J. S. Mu, Y. He and Y. Wang, Talanta, 2016, 148, 22-28.

11 Y. Jv, B. X. Li and R. Cao, Chem. Commun., 2010, 46, 80178019.

12 M. N. Karim, S. R. Anderson, S. Singh, R. Ramanathan and V. Bansal, Biosens. Bioelectron., 2018, 110, 8-15.

13 J. Chen, J. Ge, L. Zhang, Z. H. Li and L. B. Qu, Sens. Actuators, $B, 2016,233,438-444$.

14 L. Rastogi, D. Karunasagar, R. B Sashidhar and A. Giri, Sens. Actuators, B, 2017, 240, 1182-1188.

15 T. G. Choleva, V. A. Gatselou, G. Z. Tsogas and D. L. Giokas, Microchim. Acta, 2018, 185, 22.

16 H. Y. Shin, B. G. Kim, S. Cho, J. Lee, H. B. Na and M. Kim, Microchim. Acta, 2017, 184, 2115-2122.

17 J. S. Mu, Y. Wang, M. Zhao and L. Zhang, Chem. Commun., 2012, 144, 2540-2542.

18 X. W. Cheng, L. Huang, X. Y. Yang, A. A. Elzatahry, A. Alghamdi and Y. H. Deng, J. Colloid Interface Sci., 2019, 535, 425-435.

19 L. J. Huang, W. X. Zhu, W. T. Zhang, K. Chen, J. Wang, R. Wang, Q. F. Yang, N. Hu, Y. R. Suo and J. L. Wang, Microchim. Acta, 2018, 185, 7.
20 F. Nekouei, S. Nekouei, O. Jashnsaz and M. Pouzesh, Mater. Sci. Eng. C, 2018, 90, 576-588.

21 C. P. Ding, Y. H. Yan, D. S. Xiang, C. L. Zhang and Y. Z. Xian, Microchim. Acta, 2016, 183, 625-631.

22 Q. Zhong, Y. Chen, A. Su and Y. Wang, Sens. Actuators, B, 2018, 273, 1098-1102.

23 B. Wang, F. Liu, Y. Y. Wu, Y. F. Chen, B. Wen and C. M. Li, Sens. Actuators, B, 2018, 255, 2601-2607.

24 Y. J. Long, X. L. Wang, D. J. Shen and H. Z. Zheng, Talanta, 2016, 159, 122-126.

25 P. K. Yadav, V. K. Singh, S. Chandra, D. Bano, V. Kumar, M. Talat and S. H. Hasan, ACS Biomater. Sci. Eng., 2019, 5, 623-632.

26 M. L. Lin, Y. J. Guo, Z. Y. Liang, X. S. Zhao, J. N. Chen and Y. L. Wang, Microchem. J., 2019, 147, 319-323.

27 Y. J. Pang, Z. L. Huang, Y. F. Yang, Y. J. Long and H. Z. Zheng, Spectrochim. Acta, Part A, 2018, 189, 510-515.

28 Y. D. Pan, Y. F. Yang, Y. J. Pang, Y. Shi, Y. J. Long and H. Z. Zheng, Talanta, 2018, 185, 433-438.

29 J. F. Lucas, D. Castaneda and D. Hormigo, Trends Food Sci. Technol., 2017, 68, 91-101.

30 S. Y. Liu, M. Holdrich, A. S. Engler, J. Horak and M. Lammerhofer, Anal. Chim. Acta, 2017, 963, 33-43.

31 Y. J. Gu, M. L. Zhu, Y. L. Li and C. H. Xiong, Int. J. Biol. Macromol., 2018, 112, 1175-1182.

32 S. Kim, J. Lee, S. Jang, H. Lee, D. Sung and J. Chang, Biochem. Eng. J., 2016, 105, 406-411.

33 D. Ji, Y. Du, H. Meng, L. Zhang, Z. Huang, Y. Hu, J. Li, F. Yu and Z. Li, Sens. Actuators, B, 2018, 256, 512-519.

34 J. Ge, K. Xing, X. Geng, Y. L. Hu, X. P. Shen, L. Zhang and Z. H. Li, Microchim. Acta, 2018, 185, 559.

35 R. Grinyte, G. Garai-Ibabe, L. Saa and V. Pavlov, Anal. Chim. Acta, 2015, 881, 131-138.

36 X. Q. Zhang, S. W. Gong, Y. Zhang, T. Yang, C. Y. Wang and N. Gu, J. Mater. Chem., 2010, 20, 5110-5116.

37 Y. Yang, D. Shen, Y. Long, Z. Xie and H. Zheng, Sci. Rep., 2017, 7, 43141.

38 B. S. Batule, K. S. Park, S. Gautam, H. J. Cheon, M. Kim and H. G. Park, Sens. Actuators, B, 2019, 283, 749-754.

39 Z. F. Gao, A. Y. Ogbe, E. E. Sann, X. D. Wang and F. Xia, Talanta, 2018, 180, 12-17.

40 X. H. Duan, Q. Liu, G. N. Wang and X. G. Su, J. Lumin., 2019, 207, 491-496.

41 S. L. Shen, M. M. Jia, Z. H. Tang, S. Chang, P. Y. Shi and J. H. Yang, Mater. Res. Bull., 2018, 144, 471-477.

42 N. Wang, J. C. Sun, L. J. Chen, H. Fan and S. Y. Ai, Microchim. Acta, 2015, 182, 1733-1738.

43 Q. Q. Wang, X. P. Zhang, L. Huang, Z. Q. Zhang and S. J. Dong, ACS Appl. Mater. Interfaces, 2017, 9, 7465-7471.

44 L. Zhang, X. Hai, C. Xia, X. W. Chen and J. H. Wang, Sens. Actuators, B, 2017, 248, 374-384.

45 L. P. Lin, X. H. Song, Y. Y. Chen, M. C. Rong, T. T. Zhao, Y. R. Wang, Y. Q. Jiang and X. Chen, Anal. Chim. Acta, 2015, 869, 89-95. 